\title{
Kluver-Bucy Syndrome
}

National Cancer Institute

\section{Source}

National Cancer Institute. Kluver-Bucy Syndrome. NCI Thesaurus. Code C84802.

A rare syndrome resulting from damage to both temporal lobes of the brain. Signs and symptoms include oral exploratory behavior, docility, altered sexuality, dietary changes, and visual agnosia. 